\begin{abstract}
Iranica
Abstracta Iranica Revue bibliographique pour le domaine irano-aryen

Volume 32-33 | 2013

Comptes rendus des publications de 2009-2010
\end{abstract}

\title{
Rika Gyselen. Two Notes on post-Sasanian Coins
}

\section{Nikolaus Schindel}

\section{(2) OpenEdition}

\section{Journals}

Electronic version

URL: http://journals.openedition.org/abstractairanica/40506

DOI: 10.4000/abstractairanica.40506

ISSN: 1961-960X

\section{Publisher:}

CNRS (UMR 7528 Mondes iraniens et indiens), Éditions de l'IFRI

Printed version

Date of publication: 1 December 2013

ISSN: 0240-8910

\section{Electronic reference}

Nikolaus Schindel, «Rika Gyselen. Two Notes on post-Sasanian Coins », Abstracta Iranica [Online], Volume 32-33 | 2013, document 164, Online since 01 July 2016, connection on 26 September 2020. URL : http://journals.openedition.org/abstractairanica/40506 ; DOI : https://doi.org/10.4000/ abstractairanica.40506

This text was automatically generated on 26 September 2020 .

Tous droits réservés 


\title{
Rika Gyselen. Two Notes on post- Sasanian Coins
}

\author{
Nikolaus Schindel
}

\section{REFERENCES}

Rika Gyselen. «Two Notes on post-Sasanian Coins ». Res Orientales XVIII, Sources pour l'histoire et la géographie du monde iranien (224-710). Bures-sur-Yvette / Leuven, GECMO / Peeters Press, 2009, p. 143-172.

1 The author discusses the coinage of Spur, a local ruler of Zavulistan in the late 7th century. The legends and types of his issues, as well as those of related late Sasanian, Arab-Sasanian and Arab-Hephthalite coins are discussed in detail.

\section{AUTHORS}

NIKOLAUS SCHINDEL

Österreichische Akademie der Wissenschaften, Wien 